\title{
РАЗРАБОТКА И ИССЛЕДОВАНИЕ РЕЗИНОВОЙ СМЕСИ ДЛЯ ПРОКЛАДОК РЕЛЬСОВЫХ СКРЕПЛЕНИЙ
}

\author{
Е.Н. Егоров, Н.Ф. Ушмарин, С. И. Сандалов, Н.И. Кольцов
}

\begin{abstract}
ЕВГЕНИЙ НИКОЛАЕВИЧ ЕГОРОВ - кандидат химических наук, доиент, доиент кафедры физической химии и высокомолекулярных соединений химико-фармацевтического факультета ФГБОУ ВО «Чувашский государственный университет имени И.Н. Ульянова».
\end{abstract}

НИКОЛАЙ ФИЛИППОВИЧ УШМАРИН - кандидат технических наук, заместитель начальника производства резинотехнических изделий $А О$ «Чебоксарское производственное объединение имени В.И. Чапаева».

СЕРГЕЙ ИВАНОВИЧ САНДАЛОВ - кандидат технических наук, заместитель генерального директора по резинотехническому производству АО «Чебоксарское производственное объединение имени В.И. Чапаева».

НИКОЛАЙ ИВАНОВИЧ КОЛЬЦОВ - доктор химических наук, профессор, заведуюший кафедрой физической химии и высокомолекулярных соединений химико-фармацевтического факультета ФГБОУ ВО «Чувашский государственныци университет имени И.Н. Ульянова».

1428015, Чебоксары, Российская Федерация, Московский пр., 15, Чувашский государственный университет им. И.Н. Ульянова, Кафедра физическойхимии ивысокомолекулярныхсоединений.E-mail:enegorov@таil.ru, koltsovni@mail.ru.

${ }^{2}$ 428006, Чебоксары, Российская Федерация, Социалистическая, 1, Акиионерное общество «Чебоксарское производственное объединение им. В.И. Чапаева».E-mail: ushmarin@mail.ru.

Исследовано влияние транс-полинорборнена в составе композиции с маслом индустриальным И-12A на вулканизационные характеристики резиновой смеси, физико-механические, эксплуатационные и динамические свойства вулканизатов на основе комбинации бутадиен-метилстирольного, изопренового и бутадиенового каучуков. Изучаемая резиновая смесь содержала комбинацию каучуков общего назначения, серу, $N, N^{\prime}$-дитиодиморфолин, $N$-ииклогексил-2-бензотиазолсульфенамид, белила иинковые, стеариновую кислоту, $N$-изопропил- $N$ '-фенил-n-фенилендиамин, ацетонанил $H$, технический углерод $N 220$, каолин, полые корундовые микросферы НCM-L, гепсол ХКП, масло индустриальное И-12A. Резиновую смесь готовили на лабораторных вальцах ЛБ 320 160/160. Первый (базовый) вариант резиновой смеси готовился с применением масла индустриального И-12А. Второй-пятый варианты резиновой смеси готовились с добавками композиции транс-полинорборнена с И-12А. Вулканизачионные характеристики резиновой смеси изучали на реометре MDR 3000 Basic при $150^{\circ} \mathrm{C}$ в течение 20 мин. Для определения физико-механических показателей резины стандартные образиы всех вариантов резиновой смеси вулканизовали при температуре $143{ }^{\circ} \mathrm{C}$ в течение 20 мин в вулканизачионном прессе типа P-V-100-3RT-2-PCD. Исследования физико-механических, эксплуатационных и динамических свойств резины осуществлялись согласно существующим для резиновой промышленности стандартам. Показано, что вулканизаты, содержащие транс-полинорборнен в составе композиции с индустриальным маслом И-12А, обладают меньшими значениями условной прочности при растяжении, твердости и сопротивления раздиру по сравнению с вулканизатом базового варианта резиновой смеси. Увеличение содержания композиции транс-полинорборнена с маслом И-12А в резиновой смеси приводит к уменьшению изменений упруго-прочностных свойств вулканизатов после суточной выдержки в СЖР-1 при температуре $100{ }^{\circ} \mathrm{C}$ и их массы после воздействия масла индустриального И-20A при комнатной температуре. Исследования динамических параметров показывают, что увеличение содержания композищии транс-полинорборнена с маслом И-12А в резиновой смеси способствует повышению тангенса угла механических потерь и понижению модуля упругости вулканизатов. Установлено, что вул- 
канизат, включающий 55,0 мас. ч. композищии транс-полинорборнена с маслом И-12А на 100,0 мас. ч. каучуков, обладает лучшими звуко- и вибропоглощңающими свойствами.

Ключевые слова: резиновая смесь, каучуки, транс-полинорборнен, индустриальное масло И-12А, реометрические, физико-механические, эксплуатационные и динамические свойства, прокладки рельсовых скреплений.

\title{
DEVELOPMENT AND RESEARCH OF RUBBER MIXTURE FOR THE MANUFACTURE OF RAIL FASTENER GASKETS
}

\author{
E. N. Egorov ${ }^{a}$, N. F. Ushmarin ${ }^{\text {, }}$, S. I. Sandalov , N. I. Kol’tsov \\ ${ }^{a}$ Department of Physical Chemistry and Macromolecular Compounds, Chuvash State University named after \\ I.N. Ulyanov, Moskovskiy ave., 15, Cheboksary, Russia, 428015. \\ ${ }^{b}$ The Joint Stock Company "Cheboksary Production Association named after V.I. Chapaev", Socialist, 1, \\ Cheboksary, Russia, 428006.
}

The effect of trans-polynorbornene in the composition with industrial I-12A oil on the vulcanization characteristics of the rubber mixture, the physicomechanical, operational and dynamic properties of vulcanizates based on a combination of butadiene-methylstyrene, isoprene and butadiene caoutchoucs are studied. The studied rubber mixture contained a combination of general purpose caoutchoucs, sulfur, $N, N^{\prime}$-dithiodimorpholine, $N$-cyclohexyl2-benzothiazolsulfenamide, zinc white, stearic acid, $N$-isopropyl-N'-phenyl-p-phenylenediamine, acetonanil $N$, carbon black $N$ 220, kaolin, hollow corundum microspheres HCM-L, hepsol CKP, industrial oil I-12A. The rubber mixture was prepared on laboratory rollers LB 320 160/160. The first (basic) version of the rubber compound was prepared using industrial oil I-12A. The second - fifth versions of the rubber compound were prepared with additives of the trans-polynorbornene composition with I-12A. The vulcanization characteristics of the rubber mixture were studied on an MDR 3000 Basic rheometer at $150{ }^{\circ} \mathrm{C}$ for 20 minutes. To determine the physical and mechanical properties of rubber, standard samples of all variants of the rubber mixture were vulcanized at a temperature of $143{ }^{\circ} \mathrm{C}$ for $20 \mathrm{~min}$ in a vulcanization press of the type P-V-100-3RT-2-PCD. Investigations of the physicomechanical, operational, and dynamic properties of rubber were carried out in accordance with standards existing for the rubber industry. It was shown that vulcanizates containing trans-polynorbornene in the composition with industrial oil I-12A have lower values of conditional tensile strength, hardness and tear resistance compared to the vulcanizate of the base rubber compound. An increase in the content of the trans-polynorbornene composition with I-12A oil in the rubber compound leads to a decrease in the changes in the elastic-strength properties of the vulcanizates after daily exposure to SZHR-1 at a temperature of $100^{\circ} \mathrm{C}$ and their mass after exposure to industrial I-20A oil at room temperature. Studies of dynamic parameters show that an increase in the content of the trans-polynorbornene composition with I-12A oil in the rubber compound increases the tangent of the angle of mechanical loss and decreases the elastic modulus of the vulcanizates. It was found that the vulcanizate, including 55.0 mass parts the composition of trans-polynorbornene with I-12A oil per 100.0 mass parts of rubbers, has the best sound and vibration-absorbing properties.

Key-words: rubber mixture, caoutchoucs, trans-polynorbornene, industrial oil I-12A, rheometric, physico-mechanical, operational and dynamic properties, rail fastener gaskets. 


\section{Введение}

Стремление к быстрейшему преодолению расстояний - одна из естественных потребностей человека, поэтому борьба за скорость на железных дорогах ведется с момента их возникновения. Все более широкую популярность в мире получает принципиально новое направление в развитии железных дорог - высокоскоростной железнодорожный транспорт. В связи с необходимостью развития высокоскоростного железнодорожного транспорта в настоящее время в России остро стоит проблема повышения эксплуатационных характеристик подрельсовых прокладок, как элемента надежного функционирования современной транспортной системы. Эти прокладки работают в сложных условиях эксплуатации, испытывая нагрузки от подвижного состава и воздействия окружающей среды, и должны сочетать в себе высокую прочность, морозостойкость, трещиностойкость, коррозионную стойкость [1]. Увеличение скоростей движения поездов влечет повышение уровней вибрации и шума в жилой застройке [2]. Железные дороги в процессе эксплуатации создают повышенные уровни шума, вызванные взаимодействием подвижного состава и железнодорожного пути, источники шума подвижного состава также вносят свой вклад в акустическую обстановку [3]. Поэтому для решения проблемы повышения амортизационных и звукопоглощающих свойств необходимо создание резиновых прокладок скреплений для рельсов с использованием специальных полимеров. Одним из таких полимеров, применяемый в качестве виброгасящего, звукопоглощающего и демпфирующего материла, является транс-полинорборнен (ТПНБ) - трансполибицикло[2,2,1]гепт-2-ен [4-13]. В [14, 15] показана возможность использования ТПНБ для производства резиновых изделий с шумо- и звукопоглощающими свойствами. В связи с этим в данной работе исследовано влияние ТПНБ на реометрические свойства резиновой смеси, физико-механические, эксплуатационные и динамические показатели вулканизатов на основе каучуков общего назначения (бутадиен-метилстирольного, изопренового и бутадиенового) с целью разработки эффективных звукои вибропоглощающих резиновых прокладок рельсовых скреплений для железнодорожных путей.

\section{Экспериментальная часть}

Основой исследуемой резиновой смеси служила комбинация бутадиен-метилстирольного СКМС-30АРК, изопренового СКИ-3 и бутадиенового СКД каучуков, которая включала следующие ингредиенты: вулканизующие агенты - сера, N,N'- дитиодиморфолин; ускоритель вулканизации Vulkacit CZ/C (Lanxess, Германия) (N-циклогексил2-бензотиазолсульфенамид); активаторы вулканизации - белила цинковые, стеариновая кислота; противостарители - Vulkanox 4010 NA/LG (Lanxess, Германия) (N-изопропил- $\mathrm{N}^{\prime}$-фенил- $n$ фенилендиамин), ацетонанил Н (полимеризованный 2,2,4-триметил-1,2-дигидрохинолин - продукт конденсации ацетона с анилином); наполнители технический углерод N 220, каолин, полые корундовые микросферы HCM-L c размером частиц от 70 до 180 мкм); диспергатор микросфер HCM-L в каучуковой матрице - гепсол ХКП (сополимер на основе гексохлор- $n$-ксилола и хлорированного парафина); мягчитель - масло индустриальное марки И-12А. Исследуемый ТПНБ (производство компании «Astron Industriebeteiligungs $\mathrm{GmbH»,} \mathrm{Австрия)}$ представляет собой мелкозернистый порошок белого цвета с размером частиц 300-400 мкм. Непосредственное введение порошкообразного ТПНБ в резиновую смесь не представляется возможным из-за его плохого совмещения с матрицей каучуков. Для устранения этого недостатка в [16] предлагается использовать каучукоподобные смеси ТПНБ в технологических маслах. В связи с этим была разработана каучукоподобная смесь (КС) ТПНБ с маслом индустриальным И-12А с установлением оптимального их соотношения. Изготовление КС проводили в две стадии. Вначале перемешивали ТПНБ с индустриальным маслом И-12А при массовом соотношении ТПНБ : И- $12 \mathrm{~A}=1,0: 1,5$, температуре $70-80{ }^{\circ} \mathrm{C}$ в течение $1,5-2,0$ ч. Затем полученный набухший продукт подвергали вальцеванию на вальцах ВН 2102 (650 300/300) при постоянном подрезе образующегося на переднем валке вальцов запаса композиции с двух сторон этого валка в течение 20 мин при температуре валков $50-60{ }^{\circ} \mathrm{C}$. После вальцевания получали КС, которая срезалась с переднего валка в виде листа. В дальнейшем КС вводили в исследуемую резиновую смесь в различных количествах.

Первый (базовый) вариант резиновой смеси готовился с применением в качестве мягчителя масла индустриального И-12А (15,0 мас. ч. на 100,0 мас. ч. каучуков) без использования композиции КС. Второй - пятый её варианты готовились без масла индустриального И-12А с добавками 15,$0 ; 25,0 ; 40,0$ и 55,0 мас. ч. композиции КС на 100,0 мас. ч. каучуков, что соответствует содержанию ТПНБ в количествах $6,0,10,0,16,0,22,0$ мас. ч. и входящего в композицию КС масла индустриального И-12А в количествах 9,$0 ; 15,0 ; 24,0$ и 33,0 мас. ч. на 100,0 мас. ч. каучуков.

Резиновую смесь готовили на лабораторных вальцах ЛБ 320 160/160 при максимально оди- 
наковых условиях: температура валков вальцов (60-70 $\left.{ }^{\circ} \mathrm{C}\right)$, последовательность ввода ингредиентов в матрицу каучуков, цикл смешения (15 мин). Вулканизационные (реометрические) свойства резиновой смеси исследовали на реометре MDR 3000 Basic фирмы «Mon Tech» при $150{ }^{\circ} \mathrm{C}$ в течение 20 мин в соответствии с ГОСТ 12535-84. Стандартные образцы всех вариантов резиновой смеси для определения физико-механических показателей вулканизовали при температуре $143{ }^{\circ} \mathrm{C}$ в течение 20 мин в вулканизационном прессе типа P-V100-3RT-2-PCD. Основные характеристики вулканизатов определяли согласно действующим в рези- новой промышленности стандартам: упруго-прочностные свойства определяли по ГОСТ 270-75; твердость по Шору А - по ГОСТ 263-75; сопротивление раздиру - по ГОСТ 262-79; истираемость по ГОСТ 426-77; относительную остаточную деформацию сжатия - по ГОСТ 9.029-74; стойкость к действию агрессивных углеводородных сред по ГОСТ 9.030-74. Динамические параметры (модуль упругости, тангенс угла механических потерь) вулканизатов различных вариантов резиновой смеси изучались при комнатной температуpe на динамическом механическом анализаторе Metravib VHF 104 при частоте 1000 Гц, соответ-

Таблицча

Варианты и свойства резиновой смеси и вулканизатов

\begin{tabular}{|c|c|c|c|c|c|}
\hline \multirow{2}{*}{ Ингредиент, показатель } & \multicolumn{5}{|c|}{ Варианты резиновой смеси } \\
\hline & 1 & 2 & 3 & 4 & 5 \\
\hline Композиция КС, мас. ч. & - & 15,0 & 25,0 & 40,0 & 55,0 \\
\hline \multicolumn{6}{|c|}{ Реометрические показатели резиновой смеси при 150 º } \\
\hline$M_{\mathrm{H}}, д \mathrm{H} \cdot \mathrm{M}$ & 28,16 & 25,18 & 21,07 & 19,96 & 14,41 \\
\hline$M_{\mathrm{L}}$, дН·м & 4,91 & 4,04 & 3,54 & 3,03 & 2,81 \\
\hline$\Delta M, д \mathrm{H} \cdot \mathrm{M}$ & 23,25 & 21,14 & 17,53 & 16,93 & 11,60 \\
\hline$t_{\mathrm{s}}$, мин & 3,04 & 3,65 & 3,95 & 4,44 & 4,58 \\
\hline$t_{90}$, мин & 7,74 & 8,68 & 8,77 & 8,91 & 9,12 \\
\hline \multicolumn{6}{|c|}{ Физико-механические свойства вулканизатов (режим вулканизации $143{ }^{\circ} \mathrm{C} × 20$ мин) } \\
\hline$f_{100}, \mathrm{M \Pi а}$ & 6,3 & 6,1 & 5,8 & 5,2 & 4,5 \\
\hline$f_{\mathrm{p}}, \mathrm{M \Pi а}$ & 20,1 & 18,1 & 16,6 & 16,2 & 15,4 \\
\hline$\varepsilon_{\mathrm{p}}, \%$ & 330 & 360 & 370 & 390 & 410 \\
\hline H, ед. Шор А & 78 & 76 & 74 & 72 & 66 \\
\hline$B, \kappa \mathrm{H} \cdot \mathrm{M}^{-1}$ & 66 & 61 & 55 & 48 & 44 \\
\hline ОДС при 30 \% сжатии $\left(100^{\circ} \mathrm{C} \times 24\right.$ ч), \% & 20,2 & 21,7 & 22,8 & 23,9 & 25,2 \\
\hline$\alpha, \mathrm{m}^{3} \cdot \mathrm{T} Д ж^{-1}$ & 61,2 & 62,9 & 63,6 & 64,3 & 65,1 \\
\hline \multicolumn{6}{|c|}{ Изменение свойств вулканизатов после выдержки в СЖР-1 (100C×24 ч) } \\
\hline$\Delta f_{\mathrm{p}}, \%$ & $-43,8$ & $-32,6$ & $-31,1$ & $-29,6$ & $-21,1$ \\
\hline$\Delta \varepsilon_{\mathrm{p}}, \%$ & $-54,5$ & $-41,7$ & $-36,8$ & $-32,9$ & $-30,8$ \\
\hline$\Delta H$, ед. Шор А & -13 & -13 & -12 & -10 & -10 \\
\hline \multicolumn{6}{|c|}{ Изменение массы вулканизатов после воздействия агрессивных сред ( 23 C×24 ч) } \\
\hline$\Delta m$ (масло индустриальное И-20А), \% & $+3,6$ & $+3,3$ & $+2,7$ & $+2,4$ & $+2,2$ \\
\hline$\Delta m$ (вода), \% & $+0,31$ & $+0,31$ & $+0,31$ & $+0,32$ & $+0,33$ \\
\hline \multicolumn{6}{|c|}{ Динамические параметры вулканизатов при 1000 Гц } \\
\hline$E \cdot 10^{-7}$, Па & 12,92 & 10,31 & 9,43 & 7,03 & 3,87 \\
\hline $\operatorname{tg} \delta$ & 0,1392 & 0,1470 & 0,1809 & 0,2705 & 0,3162 \\
\hline
\end{tabular}

Примечание: $M_{\mathrm{H}}$ - максимальный крутящий момент; $M_{\mathrm{L}}-$ минимальный крутящий момент; $\Delta M-$ разность максимального и минимального крутящих моментов; $t_{\mathrm{s}}$ - время начала вулканизации; $t_{90}$ - оптимальное время вулканизации; $f_{100}-$ условное напряжение при $100 \%$-ном растяжении; $f_{\mathrm{p}}$ - условная прочность при растяжении; $\varepsilon_{\mathrm{p}}$ - относительное удлинение при разрыве; $H$ - твердость; $B$ - сопротивление раздиру; ОДС - относительная остаточная статическая деформация сжатия; $\alpha$-истираемость; $\Delta f, \Delta \varepsilon, \Delta m$ - относительное изменение условной прочности при растяжении, относительного удлинения при разрыве и массы; $\Delta H$ - разность твердостей резины после и до выдержки в агрессивной среде; $E$ - модуль упругости; $\operatorname{tg} \delta$ - тангенс угла механических потерь. 
ствующей резонансной частоте колебаний рельсов при движении железнодорожного транспорта.

\section{Результаты и их обсуждение}

Исследованные варианты резиновой смеси, содержащих композицию КС, их реометрические характеристики, а также физико-механические и эксплуатационные свойства вулканизатов представлены в таблице.

На рисунке приведены реометрические кривые для различных вариантов резиновой смеси при температуре $150{ }^{\circ} \mathrm{C}$. На основании этих кривых были определены вулканизационные характеристики, которые приведены в таблице.

Как видно из данных таблицы, при увеличении содержания композиции КС в резиновой смеси наблюдается уменьшение показателей максимального и минимального крутящих моментов и их разности $(\Delta \mathrm{M})$ по сравнению с базовым вариантом смеси. Это, по-видимому, связано с увеличением количества мягчителя (масла индустриального И-12А), содержащегося в композиции КС. Известно [17], что степень химического сшивания прямо пропорциональна величине $\Delta \mathrm{M}$, а, следовательно, степени сшивки вулканизата. Поэтому вулканизат пятого варианта резиновой смеси, содержащий 55,0 мас. ч. композиции КС, должен обладать наименьшей сшивкой.

Результаты исследования физико-механических свойств показывают, что вулканизаты, содержащие композицию КС, обладают меньшими значениями условного напряжения при $100 \%$-ном растяжении, условной прочности при растяжении, твердости и сопротивления раздиру по срав- нению с вулканизатом базового варианта резиновой смеси. При этом происходит возрастание показателей относительного удлинения при разрыве, относительной остаточной статической деформации сжатия (ОДС) и истираемости вулканизатов. Это связано с уменьшением вязкости резиновой смеси при увеличении содержания в ней композиции КС, что подтверждается значениями минимального крутящего момента, который косвенно характеризует вязкость смеси. Уменьшение вязкости резиновой смеси способствует увеличению сегментальной подвижности макромолекул каучуков, что приводит к возрастанию относительного удлинения при разрыве, ОДС и истираемости резины.

Исследование эксплуатационных свойств резин основывается на изучении их стойкости к воздействию агрессивных сред. Нами исследовались изменения физико-механических свойств вулканизатов после воздействия стандартной жидкости СЖР-1 при температуре $100{ }^{\circ} \mathrm{C}$ в течение 24 ч и массы резины после суточной экспозиции в масле индустриальном И-20А и воде при комнатной температуре. Результаты исследований приведены в таблице. Из данных таблицы следует, что увеличение содержания композиции КС, а, следовательно, и ТПНБ, в резиновой смеси приводит к уменьшению изменений упруго-прочностных свойств вулканизатов после суточной выдержки в СЖР1 и их массы после воздействия масла индустриального И-20А при практически не изменяющейся массе вулканизатов после суточной выдержки в воде. Наименьшими изменениями этих свойств характеризуется вулканизат пятого варианта резиновой смеси.

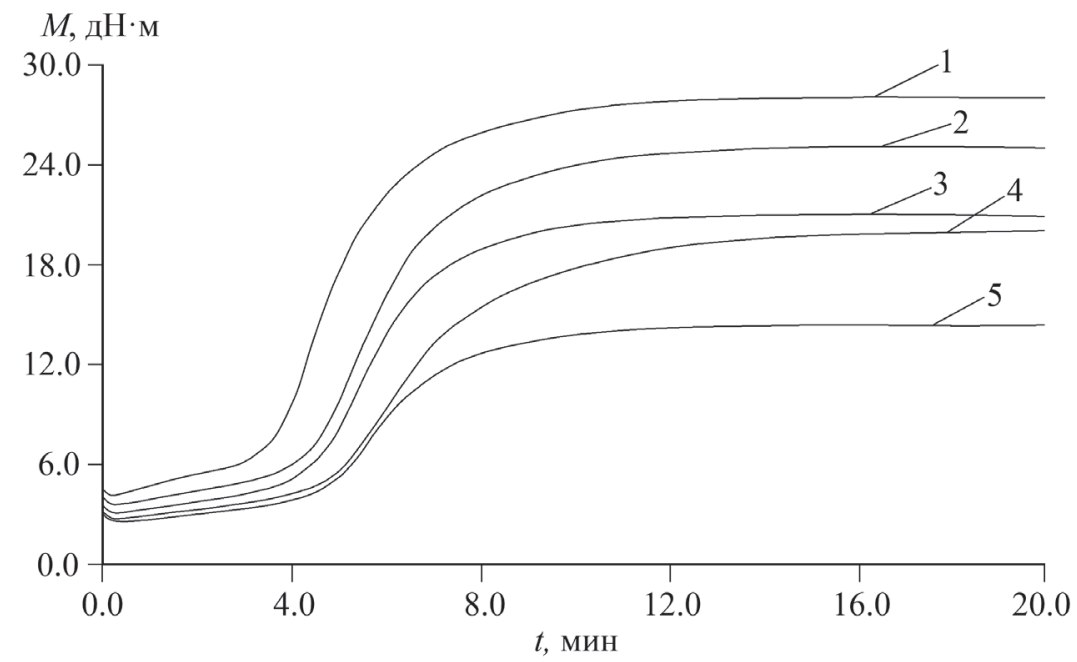

Рис. Реометрические кривые для различных вариантов резиновой смеси при $150{ }^{\circ} \mathrm{C}$ (номера кривых соответствуют номерам вариантов таблищы) 
Исследования динамических параметров при резонансной частоте 1000 Гц и комнатной температуре показывают, что увеличение содержания композиции КС в резиновой смеси способствует повышению тангенса угла механических потерь и уменьшению модуля упругости вулканизатов. Причем, для третьего варианта по сравнению с первым вариантом резиновой смеси, содержащих одинаковое количество масла индустриального И-20А (15,0 мас. ч. на 100,0 мас. ч. каучуков), значение тангенса угла механических потерь в 1,3 раза больше. Последнее, очевидно, связано с тем, что третий вариант содержит ТПНБ в составе композиции КС. Наибольшим значением тангенса угла механических потерь обладает вулканизат пятого варианта резиновой смеси, содержащий максимальное количество композиции КС, а, следовательно, ТПНБ. Известно [18-20], что с возрастанием тангенса угла механических потерь полимерных материалов увеличиваются их звуко- и вибропоглощающие свойства. Поэтому вулканизат пятого варианта резиновой смеси характеризуется лучшими этими свойствами.

Таким образом, изучено влияние ТПНБ в составе композиции КС на реометрические показатели резиновой смеси, физико-механические, эксплуатационные и динамические свойства вулканизатов на основе комбинации бутадиен-метилстирольного СКМС-30АРК, изопренового СКИ-3 и бутадиенового СКД каучуков. Вулканизаты, содержащие ТПНБ в составе композиции КС, характеризуются достаточно близкими величинами физико-механических свойств и изменениями массы после суточной тепловой выдержки в СЖР-1 и экспозиции при $23{ }^{\circ} \mathrm{C}$ в масле индустриальном И-20А и воде. Резина, включающая 55,0 мас. ч. композицию КС на 100,0 мас. ч. каучуков, по физико-механическим свойствам соответствует требованиям ГОСТ 340782017 «Прокладки рельсовых скреплений железнодорожного пути», обладает лучшими звуко- и вибропоглощающими свойствами и может быть использована в качестве основы для изготовления прокладок рельсовых скреплений железнодорожных путей.

\section{Выводы}

В ходе проведенных исследований показана возможность применения ТПНБ в составе композиции с маслом индустриальным И-20А в качестве ингредиента резиновой смеси на основе каучуков общего назначения, предназначенной для изготовления прокладок рельсовых скреплений. Вулканизат резиновой смеси, содержащий ТПНБ в составе композиции при массовом соотношении ТПНБ : масло индустриальное И- $12 \mathrm{~A}=1,0: 1,5$ и количестве композиции 55,0 мас. ч. на 100,0 мас. ч. каучуков, характеризуется лучшими звуко- и вибропоглощающими свойствами.

\section{Литература}

1. Гридчин А.М., Золотых С.Н. Вестн. БГТУ им. В.Г. Шухова. 2015. №2. С. 7-10.

2. Буторина М.В., Иванов П.В., Петряев А.В. Путь и путевое хозяйство. 2018. № 7. С. 15-19.

3. Буторина М.В., Куклин Д.А., Матвеев П.В., Олейников А.Ю. Вестн. РГУПС. 2019. №2. С. 57-65.

4. Mol J.C. J. Mol. Cat. A: Chemical. 2004. V. 213. P. 39-45. DOI: 10.1016/j.molcata.2003.10.049.

5. Yamazaki M. J. Mol. Cat. A: Chemical. 2004. V. 213. P. 81-87. DOI: 10.1016/j.molcata.2003.10.058.

6. Бермешев М.В., Грингольи М.Л., Лахтин В.Г., Финкельштейн Е.Ш. Нефтехимия. 2008. Т. 48. №4. C. $300-305$.

7. Cheng C.C., Chang C.S., Hsu Y.L., Lee T.Y., Chang L.C., Liu S.H., Wu Y.T. Eur. J. Org. Chem. 2010. N 4. P. 672-679. DOI: 10.1002/ejoc.200901039.

8. Богданова Ю.Г., Должсикова В.Д., Грингольи М.Л., Костина Ю.В., Тихонов Н.А., Алентьев А.Ю. Высокомол. соед. Сер. А. 2013. Т. 55. №8. С. 1039-1047. DOI: $10.7868 / \mathrm{S} 0507547513080011$.

9. Leimgruber S., Trimmel G. Monatsh. Chem. 2015. V. 146 . N 7. P. 1081-1097. DOI: 10.1007/s00706-0151501-0.

10. Суслов Д.С., Быков М.В., Кравченко О.В. Высокомол. соед. Сер. С. 2019. Т. 61. № 1. С. 122-151. DOI: 10.1134/S2308114719010175.

11. Qu M., Ma Y., Li C., Shi X. J. Elastomers Plast. 2016. V. 49. N 7. P. 560-573. DOI: $10.1177 / 0095244316676867$.

12. Raspolli Galletti A.M., Pampaloni G., D’Alessio A., Patil Y., Renili F., Giaiacopi S. Macromol. Rapid Commun. 2009. V. 30. N 20. P. 1762-1768. DOI: $10.1002 /$ marc. 200900248.

13. Li L., Gomes P.T., Lemos M.A.N.D.A., Lemos F., Fan Z. Macromol. Chem. Phys. 2011. V. 212. N 4. P. 367-374. DOI: $10.1002 / \mathrm{macp} .201000612$.

14. Çakmak U.D., Hiptmair F., Major Z. Mech TimeDepend Mater. 2014. V. 18. N 1. P. 139-151. DOI: 10.1007/s11043-013-9219-z.

15. Xu J., Li A., Wang H., Shen Y. Advances in Mechanical Engineering. 2016. V. 8. N 8. P. 1-16. DOI: $10.1177 / 1687814016662561$.

16. Большой справочник резинщика. Ч. 1. Каучуки и ингредиенты / Под ред. С.В. Резниченко, Ю.Л. Морозова. М.: ООО «Издательский центр «Техинформ» МАИ». 2012. $744 \mathrm{c}$.

17. Соловьева О.Ю., Гурылёва Н.Л., Тимрот С.Д., Коротаева T.A. Изв. вузов. Химия и хим. технология. 2012. T. 55. №9. C. 77-80.

18. Сытый Ю.В., Сагомонова В.А., Кислякова В.И., Большаков В.А. Труды ВИАМ: электрон. науч.-технич. журн. 2013. №3. Ст. 06. URL: http://www.viamworks.ru (дата обращения: 30.07.2015).

19. Платонов М.М., Шульдешов Е.М., Нестерова Т.А., Сагомонова В.А. Труды ВИАМ. 2016. №4 (40). C. 76-84. DOI: 10.18577/2307-6046-2016-0-4-9-9.

20. Волочкой А.Н., Юркин Ю.В., Авдонин В.В. Инж. вестн. Дона. 2019. № 8(59). С. 35. 